\title{
Experimental Research on Influencing Factors and Ratio Optimization of New High Fluidity Borehole Sealing Material
}

\author{
Xin GUO, Sheng XUE*, Chunshan ZHENG, ${ }^{*}$ Yaobin LI
}

\begin{abstract}
This paper takes the fluidity of the sealing material as the main research indicators. Using the Design-Expert 8.0 .5 trial software designed orthogonal experiments and establishing a quadratic model between liquidity and each test factor, which showed the impact of each key factor on the fluidity, the optimal ratio of high-fluidity borehole sealing materials was obtained. The results showed that the key factors had the following order of significance: water-cement reducing agent $>$ water-cement ratio $>$ retarder > expansion agent, comprehensive consideration of expansion rate, compressive strength and setting time. The optimal percentages were found for the high-fluidity borehole sealing material: a water-cement ratio of 1 , along with $0.03 \%$ retarder, $0.5 \%$ water reducer, and $8 \%$ expansion agent. These research results could provide a reference for improving the performance of gas drainage borehole sealing materials and enhancing the effect of gas drainage.
\end{abstract}

Keywords: borehole sealing material; high fluidity; optimal ratio; orthogonal experiment; significance

\section{INTRODUCTION}

China has a high frequency of gas disaster accidents. With the increasing mining depth of coal resources, China is faced with increasingly serious gas problems, which pose a serious threat to the safety and efficiency of coal mining [13]. In order to prevent gas accidents during coal mining, gas pre-drainage technology is usually used to extract the gas from coal seams. However, the effect of gas drainage in China is generally poor. In addition to the low air permeability of the coal seam, the performance of the borehole sealing material also affects the drilling and sealing effect to a large extent. The borehole sealing materials commonly used in China's coal mines include cement mortar and polyurethane materials. However, these materials have poor penetration in micro fissures smaller than $0.1 \mathrm{~mm}$, and the cracks are closed under high stress [4], resulting in poor sealing effects. This requires a borehole sealing material with good fluidity to allow it to be effectively injected into the fine cracks in the coal and rock mass [5-6]. Ultra-fine cement prepared by refining ordinary cement particles can meet the injection requirements for fine cracks. Compared with traditional borehole sealing materials, ultrafine cement materials have higher strength, better durability, and nontoxicity [7-9]. However, to ensure that the borehole sealing material can be efficiently injected into the fine cracks of the coal and rock mass, in addition to having high fluidity, it should also have relatively high stability, a certain degree of micro-swelling, and a suitable setting time [10].

Scholars in China and abroad have conducted numerous studies on ultrafine cement. Hogancamp et al. [11] found that carbon nanofibers could increase the shrinkage and crack resistance of ultra-fine cement mortar while maintaining the hardness. Miaoet al. [12] studied the influence of the content and fineness of limestone powder on the rheological properties of cement paste: the fluidity of cement slurry increases with the increase in the content of limestone powder, and the fineness of limestone powder increases. Zhang et al. [13] added $0.56 \%$ aluminum powder and $2 \%$ gypsum to Portland cement and mixed them with a water-cement ratio of 0.6 to produce a CF sealing material, and compared the new CF sealing material with ordinary cement. There is difference between permeability and fluidity. The research results show that the new CF sealing slurry has better fluidity and permeability than ordinary cement, indicating that the new CF sealing material has better sealing performance than ordinary cement. Wongkornchaowalit et al. [14] studied the influence of polycarboxylic acid superplasticizer on the fluidity of Portland cement. The research results proved that when the polycarboxylic acid superplasticizer was $1.8 \%-2.4 \%$, the fluidity of cement has increased substantially. Chen et al. [15] studied the fluidity of ordinary cement materials with different amounts of ultrafine cement. Guo et al. [16] developed a composite ultrafine cement slurry by adding acrylate copolymer R161 and acrylate S400 to ultrafine cement, which showed good stability and injectability. Wang et al. [17] studied the fluidity of cement slurries with different glass fiber ratios. Adding glass fibers to pure cement slurries will reduce the fluidity of pure cement slurries. And with the increase of the glass fiber content, the fluidity of this cement slurry is also lower.

Previous studies on the modification of ultrafine cement had a goal of improving the performance from one aspect, with no modification method simultaneously taking into account high fluidity, expansibility, and strength. This study used ultra-fine silicate ultra-mud as the base material and added a calcium oxide-calcium sulfate composite as a swelling agent, and polycarboxylic acid as a water-reducing agent and retarder, to develop a new type of borehole sealing material that considered the material's compressive strength, fluidity, and swelling rate (the swelling rate of a test block after 60 days of curing). As the basis for judgment, the best admixture and water-to-material ratio were determined using the single factor experiment method and orthogonal experiment method.

\section{MATERIALS AND METHODS \\ 2.1 Experimental Materials}

The new type of borehole sealing material was based on ultra-fine Portland cement. The ultra-fine cement used in the experiment was produced by Shandong Kangjing New Material Technology. The appearance was a gray powder. The measured D90 value was $12.6 \mu \mathrm{m}$, and the measured D50 value was $5 \mu \mathrm{m}$. In addition, all the 
technical parameters and indicators met the requirements of "Superfine Portland Cement" (GB/T35161-2017). Its chemical composition is provided in Tab. 1 . The expansion agent used in this experiment was a calcium oxide-calcium sulfate composite expansion agent (HCSA) produced by Shijiazhuang City Functional Building Materials Co., Ltd., and it had the appearance of an off-white powder. Its components are listed in Tab. 1. The polycarboxylic acid water-reducing agent (PCE) used in the experiment was produced by FuyangChengnanBuilding Materials Co., Ltd. It was a white powder that was easily soluble in water, and the water reduction rate was $20-35 \%$. The retarder used in this experiment was seaweed powder produced by Jiangsu Changzhou Angu Waterproof Material Co., Ltd. The seaweed powder had the appearance of a white powder and was easily soluble in water. The solution was a colorless and transparent viscous liquid. Water was used to formulate a solution with a mass ratio of 1:130.

Table1 Chemical composition of raw materials

\begin{tabular}{|c|c|c|c|c|c|c|c|c|}
\hline Chemical composition & $\mathrm{SiO}_{2}$ & $\mathrm{Al}_{2} \mathrm{O}_{3}$ & $\mathrm{Fe}_{2} \mathrm{O}_{3}$ & $\mathrm{CaO}$ & $\mathrm{MgO}$ & $\mathrm{SO}_{3}$ & $\mathrm{Loss}$ & $\mathrm{Total}$ \\
\hline HCSA expanding agent & 4.96 & 8.52 & 0.99 & 64.18 & 2.67 & 16.97 & 1.19 & 99.48 \\
\hline Superfine Portland cement & 20.57 & 9.89 & 3.08 & 57.65 & 2 & 2.7 & 2.6 & 98.49 \\
\hline
\end{tabular}

\subsection{Experimental Method}

Researchers have found that the addition of a retarder [18] can enable to control the setting time, and HCSA [1921] will help cement hydration products to form a good spatial structure and improve the expansion performance, while the addition of PCE has a dispersing effect on cement particles and can improve the workability of cement and reduce unit water consumption [22-23]. Use Design-Expert 8.0.5 trial software to design the orthogonal experiment (Tab. 2). A total of 29 sets of experiments were carried out with the four factors and three levels, and the fluidity of the test block was taken as the response value [18, 24-27]. After the completion of the orthogonal experiment, the Design-Expert 8.0.5 trial software was used to calculate the variance and range of the experimental data and study the effect of the compound mixing of various additives on the performance of the sealing material. Finally, a response surface regression analysis was performed on the results of the orthogonal experiment and a quantitative regression model reflecting the relationship between the compound dosing amount of the admixture and each filling performance index was obtained, which provided a basis for the optimization of the borehole sealing material formulation [28].

In the experiment, the standard triple test mold $(70.7$ $\mathrm{mm} \times 70.7 \mathrm{~mm} \times 70.7 \mathrm{~mm}$ ) was first prepared. Then, the dry material and water quantities required for the production of the test piece were calculated according to the proportions in Tab. 2 and Tab. 3. After mixing with water, the weighed ultra-fine cement, expansion agent, and water-reducing agent were added together and mixed thoroughly. Finally, water was added for thorough mixing and pouring into the mold (Fig. 1), which was placed in the curing box for curing (temperature $20 \pm 2{ }^{\circ} \mathrm{C}$, humidity above $95 \%$ ).

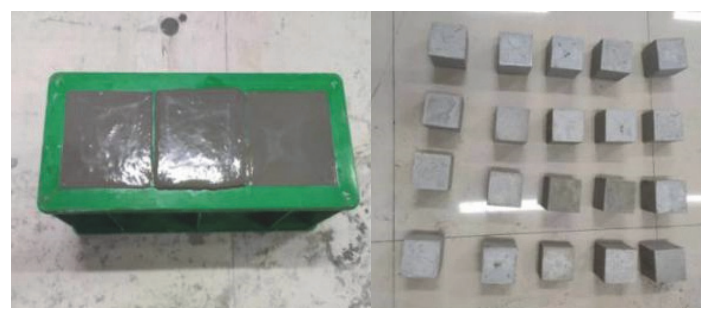

Figure 1 Preparation of sample

The fluidity test of the borehole sealing material was conducted using the specified determination method for cement mortar fluidity (GB/T2419-2005), which was expressed by the diffusion diameter $(\mathrm{mm})$ of the slurry on a horizontal glass plate. The truncated cone mold had an upper mouth diameter of $36 \mathrm{~mm}$, a lower mouth diameter of $60 \mathrm{~mm}$, and a height of $60 \mathrm{~mm}$. The evenly stirred cement slurry was placed in a round mold, the surface was flattened, and the round mold was quickly lifted off. After the cement slurry flowed, the average of the two perpendicular diameters was measured as the maximum fluidity (Fig. 2).

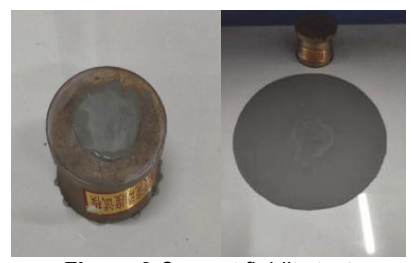

Figure 2 Cement fluidity test

The standard cement consistency water consumption, setting time, and stability test method (GB/T1346-2011) were used to measure the setting time. TUse cement slurry standard consistency setting time tester (Vicat meter) to measure setting time. First zero the Vicat meter. Then, water was separately added to the new borehole sealing material, which was evenly mixed and poured into test molds, and placed in the curing box for curing after being leveled. Finally, the initial and final setting times of the material were measured according to the national standard.

Different materials were added to pure cement and mixed to form cement slurries. After molding, the initial volume was recorded as V1. The volume was read at corresponding time intervals, and the expansion rate was tested for two months.

$\varepsilon_{t}=\frac{V_{n}-V_{1}}{V_{1}} \times 100 \%$

The sample strength test utilized the standard cement mortar strength inspection method (GB/T50080-2016), with an RMT uniaxial press used to test the compressive strength of samples with different ages. Place the test piece on the lower plate or back plate of the testing machine and start the testing machine. During the test, the load should be applied continuously and evenly. When the test piece is about to fail and begin to quickly deform, please stop adjusting the throttle of the testing machine until it fails. Then record the load. 
Use Design-Expert software to analyze the test results. First click the Analysis button to test the significance of the linear function, 2FI model, second-order model, and thirdorder model, and pass the model significance test, lack of fit item detection, and correlation. Compare the tested data and recommend a suitable model. Then (click the ANOVA button) to perform analysis of variance and significance test according to the selected model. In the analysis of variance, the significance of the constant term, the first term, the quadratic term (interaction term), and the square term (surface effect) that affect the quadratic equation model will be tested. By analyzing the response surface curve and contour map, it can be intuitively seen that the model has extreme points and the range of corresponding optimal process parameters. You can also use the software optimization function. Click the Optimization button in the Design-Expert software, and then click Numerical, and select the maximum response value within the range of experimental factors to optimize the best conditions.

Table 2 Value range of each factor in orthogonal experiment

\begin{tabular}{|c|c|c|c|c|}
\hline \multirow{2}{*}{ Test group } & \multicolumn{3}{|c|}{ Value range of each factor/\% } \\
\cline { 2 - 4 } & Water-cement ratio & Retarder & Water-reducing agent & Expanding agent \\
\hline ZJ1-29 & $0.8-1.0$ & $0.03-0.05$ & $0.3-0.5$ & $8-10$ \\
\hline
\end{tabular}

\section{RESULTS AND DISCUSSION}

\subsection{Model Establishment}

First, it was necessary to select a suitable model to fit the results, and the results of the orthogonal experiment (listed in Tab. 3) were input into the Design-Expert 8.0.5 software to fit different models. The fitting results are listed in Tab. 4 and Tab. 5. The Design-Expert software recommended the use of linear equation models and quadratic equation models, which had better fits than other models. From Tab. 4, it can be seen that the linear equation and quadratic equation models had larger $F$ values. The Prob $>F$ values were small, indicating that the two fitting models were the most significant. At the same time, it can be seen from Tab. 5 that the sum of the squared prediction residuals is low in several models. However, the $R^{2}$ value of the linear model is 0.685 , which is smaller than the $R^{2}$ value of the quadratic equation model (0.9144), indicating that the model's correlation with the experimental results is low.

Table 3 Orthogonal test results

\begin{tabular}{|c|c|c|c|c|c|c|c|c|c|c|c|}
\hline NO & $A$ & $B / \%$ & $C / \%$ & $D / \%$ & $R_{3 \mathrm{~d}} / \mathrm{MPa}$ & $\begin{array}{l}R_{7 \mathrm{~d}} / \\
\mathrm{MPa}\end{array}$ & $\begin{array}{l}R_{28 \mathrm{~d}} / \\
\mathrm{MPa}\end{array}$ & Fluidity / mm & $\begin{array}{c}\text { Initial setting } \\
\text { time / min }\end{array}$ & $\begin{array}{c}\text { Final setting } \\
\text { time / min }\end{array}$ & $\begin{array}{c}\text { Expansion } \\
\text { rate } / \%\end{array}$ \\
\hline 1 & 0.8 & 0.03 & 0.4 & 9 & 29.899 & 32.069 & 41.597 & 213.5 & 440 & 469 & 1.897 \\
\hline 2 & 0.8 & 0.04 & 0.5 & 9 & 37.697 & 38.477 & 42.833 & 226 & 419 & 437 & 2.032 \\
\hline 3 & 0.8 & 0.04 & 0.4 & 10 & 30.986 & 32.991 & 38.969 & 190.5 & 410 & 430 & 3.281 \\
\hline 4 & 0.8 & 0.04 & 0.3 & 9 & 33.997 & 35.01 & 39.021 & 199 & 406 & 443 & 1.931 \\
\hline 5 & 0.8 & 0.04 & 0.4 & 8 & 39.918 & 42.197 & 41.398 & 185.5 & 431 & 458 & 1.593 \\
\hline 6 & 0.8 & 0.05 & 0.4 & 9 & 31.652 & 34.133 & 37.256 & 207.5 & 461 & 490 & 1.821 \\
\hline 7 & 0.9 & 0.03 & 0.5 & 9 & 28.479 & 32.141 & 36.966 & 242 & 343 & 376 & 1.898 \\
\hline 8 & 0.9 & 0.03 & 0.4 & 10 & 26.943 & 28.511 & 34.981 & 218.5 & 344 & 368 & 2.471 \\
\hline 9 & 0.9 & 0.03 & 0.4 & 8 & 30.931 & 32.871 & 38.996 & 234 & 416 & 438 & 1.614 \\
\hline 10 & 0.9 & 0.03 & 0.3 & 9 & 27.696 & 31.233 & 37.061 & 179 & 337 & 370 & 1.521 \\
\hline 11 & 0.9 & 0.04 & 0.4 & 9 & 28.601 & 30.381 & 36.983 & 193 & 430 & 456 & 2.053 \\
\hline 12 & 0.9 & 0.04 & 0.4 & 9 & 28.601 & 30.381 & 36.983 & 193 & 430 & 456 & 2.053 \\
\hline 13 & 0.9 & 0.04 & 0.3 & 10 & 31.239 & 32.011 & 34.882 & 153.5 & 424 & 449 & 2.329 \\
\hline 14 & 0.9 & 0.04 & 0.4 & 9 & 28.601 & 30.381 & 36.983 & 193 & 430 & 456 & 2.053 \\
\hline 15 & 0.9 & 0.04 & 0.5 & 8 & 34.312 & 38.021 & 37.409 & 212 & 437 & 463 & 1.589 \\
\hline 16 & 0.9 & 0.04 & 0.5 & 10 & 31.213 & 32.997 & 34.411 & 243 & 422 & 444 & 2.809 \\
\hline 17 & 0.9 & 0.04 & 0.3 & 8 & 32.986 & 36.021 & 37.311 & 183.5 & 431 & 457 & 1.621 \\
\hline 18 & 0.9 & 0.04 & 0.4 & 9 & 28.601 & 30.381 & 36.983 & 193 & 430 & 456 & 2.053 \\
\hline 19 & 0.9 & 0.04 & 0.4 & 9 & 28.601 & 30.381 & 36.983 & 193 & 430 & 456 & 2.053 \\
\hline 20 & 0.9 & 0.05 & 0.3 & 9 & 25.896 & 28.033 & 33.767 & 153.5 & 482 & 518 & 1.621 \\
\hline 21 & 0.9 & 0.05 & 0.5 & 9 & 26.062 & 29.133 & 36.761 & 247 & 360 & 395 & 1.812 \\
\hline 22 & 0.9 & 0.05 & 0.4 & 10 & 26.993 & 27.012 & 33.761 & 167 & 365 & 393 & 2.597 \\
\hline 23 & 0.9 & 0.05 & 0.4 & 8 & 28.922 & 30.41 & 34.562 & 185 & 490 & 525 & 1.531 \\
\hline 24 & 1 & 0.04 & 0.3 & 9 & 27.664 & 29.008 & 33.678 & 179 & 420 & 454 & 1.986 \\
\hline 25 & 1 & 0.03 & 0.4 & 9 & 26.295 & 28.091 & 32.019 & 240 & 349 & 376 & 1.778 \\
\hline 26 & 1 & 0.04 & 0.4 & 10 & 26.513 & 27.978 & 28.072 & 230 & 359 & 386 & 2.093 \\
\hline 27 & 1 & 0.05 & 0.4 & 9 & 23.997 & 27.843 & 31.907 & 229.5 & 475 & 503 & 1.803 \\
\hline 28 & 1 & 0.04 & 0.4 & 8 & 28.911 & 31.036 & 38.213 & 207.5 & 439 & 463 & 1.302 \\
\hline 29 & 1 & 0.04 & 0.5 & 9 & 27.476 & 29.989 & 33.778 & 280 & 422 & 457 & 1.889 \\
\hline
\end{tabular}

Table 4 ANOVA results of different models

\begin{tabular}{|c|c|c|c|c|c|c|}
\hline Source & Sum of Squares & $\mathrm{d} f$ & Mean Square & $F$ Value & $p$ - value Prob $>F$ & \\
\hline Mean vs Total & $1.229 \mathrm{E}+006$ & 1 & $1.229 \mathrm{E}+006$ & & & \\
\hline Linear & 16806.13 & 4 & 4201.53 & 13.04 & $<0.0001$ & Suggested \\
\hline $2 \mathrm{FI}$ & 2615.00 & 6 & 435.83 & 1.53 & 0.2236 & \\
\hline Quadratic & 3015.67 & 4 & 753.92 & 5.03 & 0.0101 & Suggested \\
\hline Cubic & 1884.63 & 8 & 235.58 & 6.58 & 0.0169 & \\
\hline Residual & 214.77 & 6 & 35.80 & & & \\
\hline Total & $1.254 \mathrm{E}+006$ & 29 & 43239.47 & & & \\
\hline
\end{tabular}




\begin{tabular}{|c|c|c|c|c|c|c|}
\multicolumn{9}{|c}{ Table 5 Comprehensive statistical analysis of multiple models } \\
\hline Source & Std. Dev. & $R$ - Squared & Adjusted $R$ - Squared & Predicted $R$ - Squared & PRESS & 11701.95 \\
\hline Linear & 17.95 & 0.6850 & 0.6324 & 0.5231 & Suggested \\
\hline 2FI & 16.86 & 0.7915 & 0.6757 & 0.3841 & 15111.63 & \\
\hline Quadratic & 12.25 & 0.9144 & 0.8289 & 0.5072 & 12092.52 & Suggested \\
\hline Cubic & 5.98 & 0.9912 & 0.9592 & -0.2605 & 30927.00 & \\
\hline
\end{tabular}

Thus, the model is inaccurate. The Adj $R^{2}$ value of the linear model is small compared with that of the quadratic equation model, indicating that the model still needs further development. Based on these results, the experiment initially selected the quadratic equation model for fitting.

\subsection{Model Verification}

Although the conformity degree of each model was compared when the model was selected, the comparison terms ( $F$ value, $R^{2}$, etc.) were relatively abstract. Therefore, it was still necessary to verify the selected model in other ways. The studentized residual was used to draw a comparison between the predicted residual value and the actual value (Fig. 3). The abscissas of the points on the map were mostly concentrated in the center, and the distribution of the points was also approximately a straight line, indicating that the model prediction was reliable.

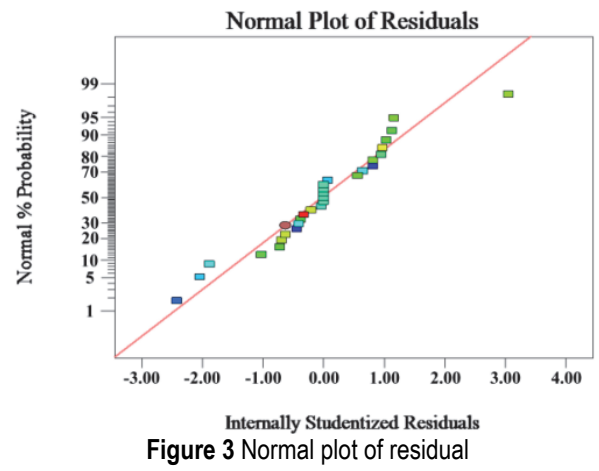

\subsection{Variance Results and Significance Tests}

From Tab. 6, it can be seen that the $F$ value of the model is 10.69 , the Prob $>F$ value is less than 0.0001 , and the correction coefficient of determination (Adj $R 2$ ) is 0.8289 , which shows that the model fits the data well and the experimental error is small. From the significance test, it can be seen that the factors had the following order of significance: $C$ (water-reducing agent) $>A$ (water-cement ratio) $>B$ (retarder) $>D$ (expansion agent). The factor combinations had the following order: $A C$ (water-cement ratio, water-reducing agent) $>C D$ (water-reducing agent, expansion agent $)>B C$ (retarder, water-reducing agent $)>$ $A D$ (water-cement ratio, expansion agent) $>A B$ (watercement ratio, expansion agent) $>B D$ (retarder, expansion agent). Among these, the Prob $>F$ value of the $C$ factor was less than 0.0001, which indicated that the index was extremely significant, and the Prob $>F$ values of factors $A$ and $B$ were less than 0.005 , which indicated that these two indicators were significant; the interaction of $A C$ was the most significant, and the interaction of $B D$ was the least significant.

Table 6 Response surface quadratic model and analysis of variance results

\begin{tabular}{|c|c|c|c|c|c|c|}
\hline Source & Sum of Squares & $\mathrm{d} f$ & Mean Square & $F$ & Prob $>F$ & Significance \\
\hline Model & 22436.79 & 14 & 1602.63 & 10.69 & $<0.0001$ & $* * *$ \\
\hline$A$ & 1728.00 & 1 & 1728.00 & 11.52 & 0.0044 & $* *$ \\
\hline$B$ & 1575.52 & 1 & 1575.52 & 10.51 & 0.0059 & $* *$ \\
\hline$C$ & 13500.52 & 1 & 12838.02 & 90.03 & $<0.0001$ & $* * *$ \\
\hline$D$ & 2.08 & 1 & 2.08 & 0.014 & 0.9078 & $*$ \\
\hline$A B$ & 5.06 & 1 & 5.06 & 0.034 & 0.8569 & $*$ \\
\hline$A C$ & 1369.00 & 1 & 1369.00 & 9.13 & 0.0092 & $* *$ \\
\hline$A D$ & 76.56 & 1 & 76.56 & 0.51 & 0.4866 & $*$ \\
\hline$B C$ & 232.56 & 1 & 232.56 & 1.55 & 0.2334 & $*$ \\
\hline$B D$ & 1.56 & 1 & 1.56 & 0.010 & 0.9201 & $*$ \\
\hline$C D$ & 930.25 & 1 & 930.25 & 6.20 & 0.0259 & $* *$ \\
\hline$A^{2}$ & 2200.05 & 1 & 2200.05 & 14.67 & 0.0018 & $* *$ \\
\hline$B^{2}$ & 582.84 & 1 & 582.84 & 3.89 & 0.0688 & $*$ \\
\hline$C^{2}$ & 327.37 & 1 & 327.37 & 2.18 & 0.1617 & $*$ \\
\hline$D^{2}$ & 95.32 & 1 & 95.32 & 0.64 & 0.4386 & $*$ \\
\hline Residual & 2099.40 & 14 & 149.96 & & & \\
\hline Lack of Fit & 2099.40 & 10 & 209.94 & & & \\
\hline Pure Error & 0.000 & 4 & 0.000 & & & \\
\hline Cor Total & 24536.19 & 28 & & & & \\
\hline & & \multicolumn{5}{|c|}{$\begin{array}{l}\text { The values of Prob in this article represent the significant degree of influence of all factors on liquidity.*** } \\
\text { value }(-\infty, 0.0001) ; * * P \text { value }(0.0001,0.05) ; * P \text { value }(0.05,+\infty)\end{array}$} \\
\hline
\end{tabular}

\subsection{Response Surface Analysis}

The response surface drawn according to the binomial polynomial regression equation was a three-dimensional surface obtained by the interaction of the response values of the independent variables. The response value (liquidity) could be predicted and optimized, and any two factors could also be adjusted to analyze their interaction and 
obtain the interaction rules. It was possible to determine when any two of the four factors ( $A$ (water-cement ratio), $B$ (retarder content), $C$ (water-reducing agent content), and $D$ (expansion agent content)) remained unchanged by the interaction and laws of the other two factors.

Fig. 4 shows the effect of the water-cement ratio and water-reducing agent on the fluidity results. It can be seen from Fig. 4 that the fluidity varies greatly with the watercement ratio or water-reducing agent, and the response surface is steep at this time. As reflected in the contour map, the contour lines are dense. The rapid color change in the contour map also proves that the slope of the response surface is large. This indicates that the water-cement ratio and interaction of the water-reducing agent have a significant impact on the response value, which is consistent with the previous variance analysis results for each item. The two factors of the ash ratio and waterreducing agent have a more significant influence on the test results.
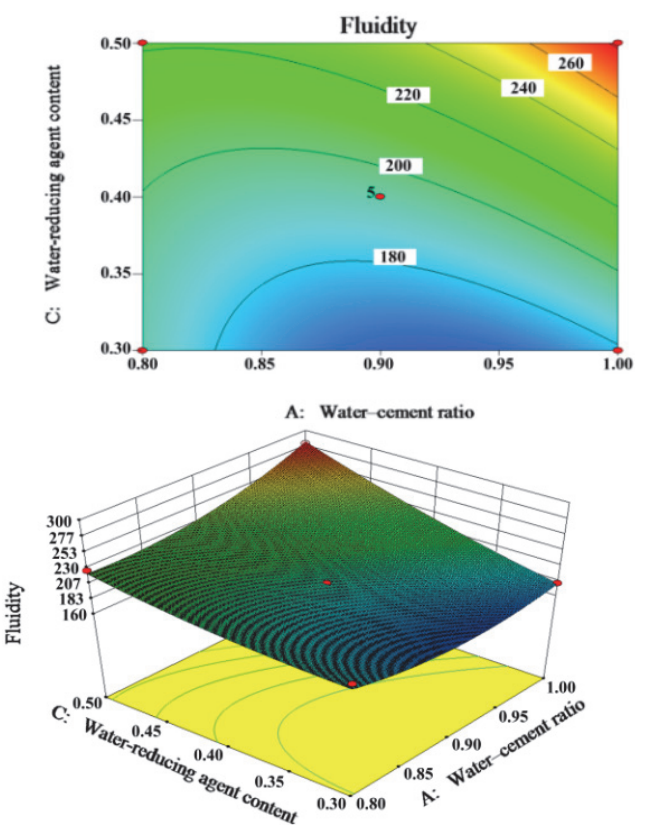

Figure 4 Effect of water-cement ratio and water reducer on fluidity
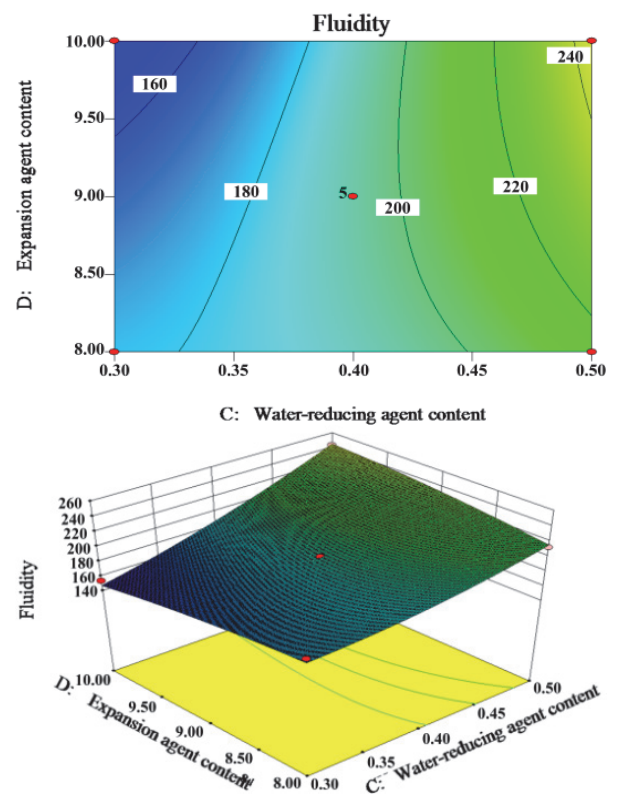

Figure $5 \mathrm{Effect}$ of water-reducing agent and expansion agent on fluidity
Fig. 5 shows the effect of the water-reducing agent and expansion agent on the fluidity results. It can be seen from Fig. 5 that when the water-reducing agent and expansion agent are taken at the upper limits of their selected level ranges, the fluidity change trend is relatively steep, indicating that the interaction between the time-reducing agent and expansion agent has a significant impact on the response value. The contour distribution trend is related to the factor level, and there is a certain distortion in the threedimensional surface graph. The interaction of these two factors affects the particle flow, and the dense contour lines on the abscissa also indicate that the water-reducing agent has a greater impact on fluidity.

Fig. 6 shows the effect of the retarder and waterreducing agent on the fluidity results. It can be seen from Fig. 6 that the contour lines on the ordinate are denser, while the contour lines on the abscissa are sparse, indicating that the retarder has a greater impact on fluidity. When the upper limit of the content of the retarder is used, the response surface is relatively smooth, indicating that the retarder has a certain influence on the fluidity, but the range of this influence is small.
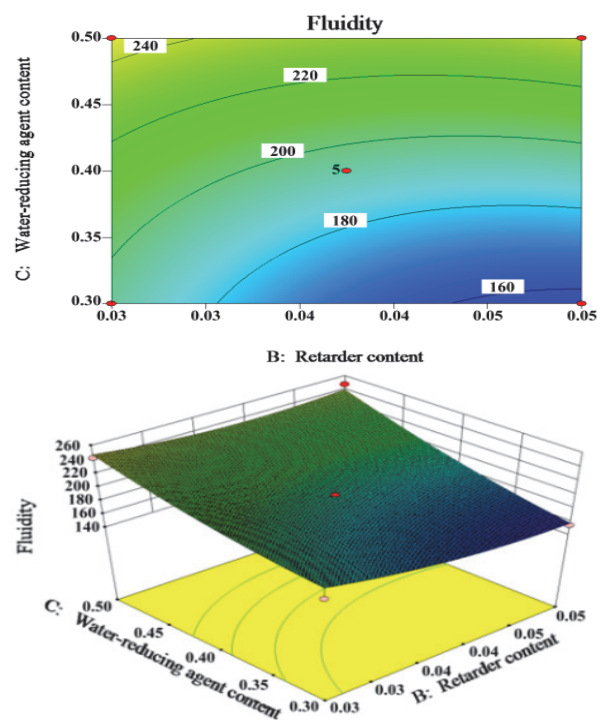

Figure $6 \mathrm{Effect}$ of retarder and water-reducing agent on fluidity
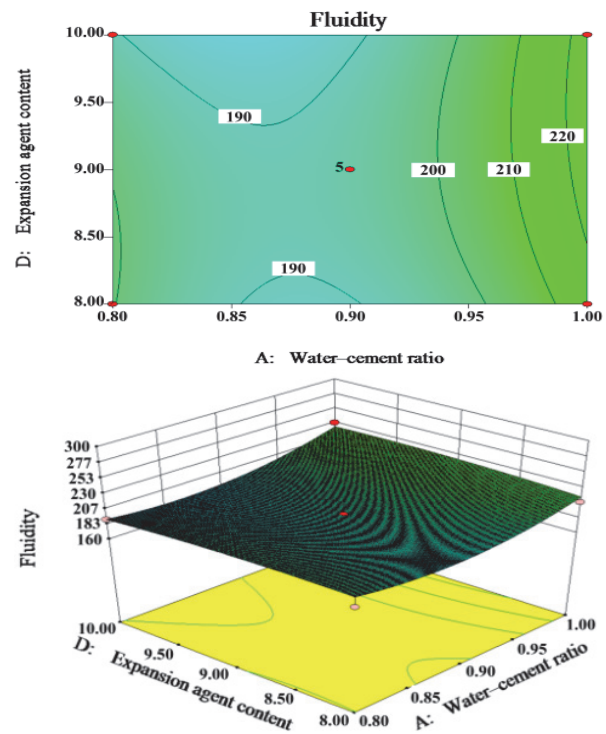

Figure 7 Effect of water-cement ratio and expansion agent on fluidity 
Fig. 7 shows the effect of the water-cement ratio and expansion agent on the fluidity results. It can be seen from Fig. 7 that the contour lines of the ordinate are sparse and the contour lines of the abscissa are dense, indicating that the water-cement ratio has a greater impact on the fluidity. The expansion agent has little effect on the fluidity; the response surface is relatively smoother, indicating that the interaction of the two factors has a certain impact on the fluidity, but the range of this influence is small. When using the upper limits of the two factors, the response surface is steep, indicating that the interaction of the two factors has the greatest impact on the liquidity at this time.
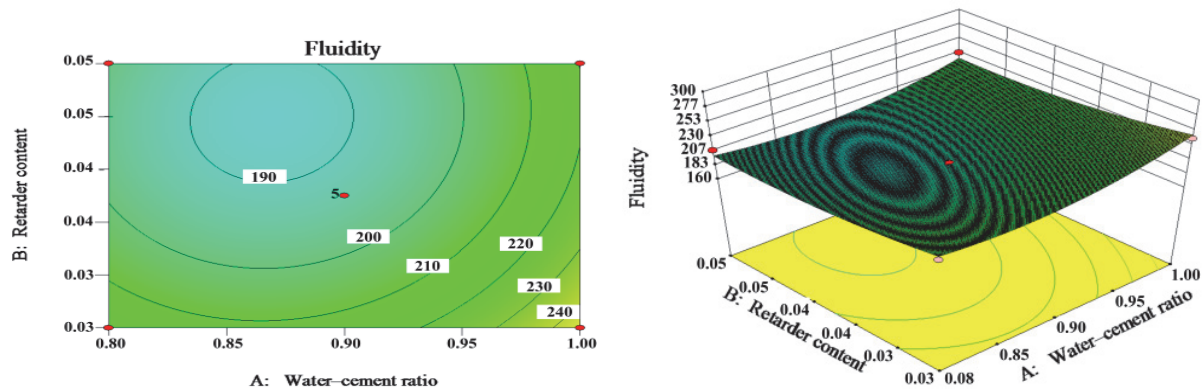

Figure 8 Effect of water-cement ratio and retarder on fluidity
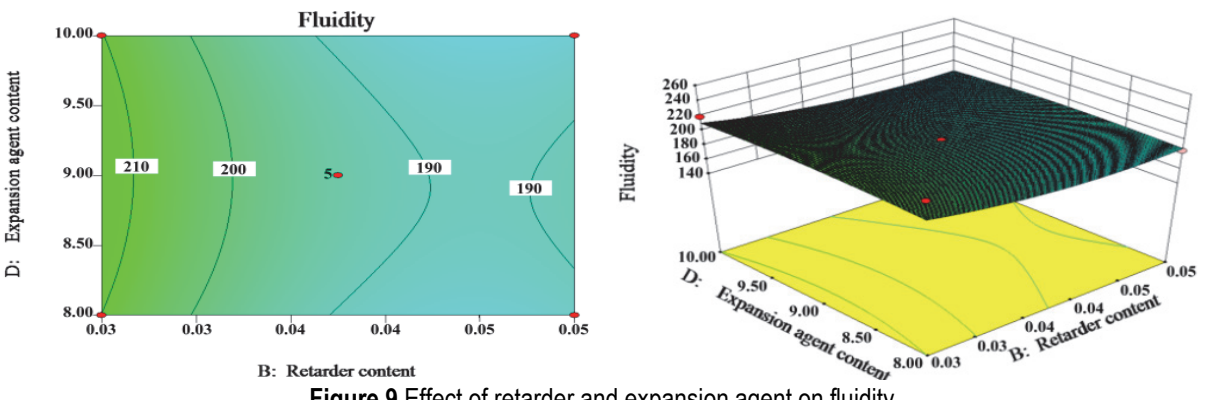

Figure 9 Effect of retarder and expansion agent on fluidity

Fig. 8 shows the effect of the water-cement ratio and retarder on the fluidity results. The shape of the contour reflects the strength of the interaction effect. A circle indicates that the interaction of the two factors is not significant, while an ellipse shows the opposite. It can be seen from Fig. 8 that the distribution of the abscissa contour lines is denser than that on the ordinate, indicating that the influence of the water-cement ratio on the response value is more significant than that of the retarder. The pattern change law is similar to the response obtained by the two-factor analysis of variance in the figure. The influence law of the value is the same, and the graph has a certain distortion. When the water-cement ratio is at the upper limit and the retarder is at the lower limit, the response surface is steep, but the overall response surface is relatively flat, indicating a certain interaction between the two factors, but the effect is small.

Fig. 9 shows the effect of the retarder and expansion agent on the fluidity results. As shown in Fig. 9, the contour lines on the abscissa are dense, while the contour lines on the ordinate are sparse, indicating that the influence of the coagulant on the fluidity is greater than that of the expansion agent. This is consistent with the results of the analysis of variance, and the response surface is the smoothest when the retarder interacts with the expansion agent, indicating that the interaction between the retarder and expansion agent has the least significant effect on the fluidity.

\subsection{Parameter Optimization and Verification}

The Design-Expert software was used for further analysis of the experimental results, using the fluidity as the optimization index to obtain the optimized experimental program by selecting the first six groups of optimized experimental programs, and verifying them, as shown in Tab. 7.

Table 7 Optimization scheme and results

\begin{tabular}{|c|c|c|c|c|c|c|c|}
\hline \multirow[b]{2}{*}{ NO } & \multicolumn{4}{|c|}{ Experimental optimization ratio } & \multirow{2}{*}{$\begin{array}{c}\text { Forecast } \\
\text { liquidity / } \\
\text { mm }\end{array}$} & \multirow{2}{*}{$\begin{array}{c}\text { Measured } \\
\text { liquidity / } \\
\text { mm }\end{array}$} & \multirow[b]{2}{*}{ Error $/ \%$} \\
\hline & Water-cement ratio & Retarder / \% & Water reducing agent $/ \%$ & Expansion agent / \% & & & \\
\hline 1 & 1 & 0.03 & 0.5 & 8.00 & 288.494 & 288.4 & -0.034 \\
\hline 2 & 0.99 & 0.03 & 0.49 & 9.11 & 287.832 & 287 & -0.289 \\
\hline 3 & 0.98 & 0.04 & 0.5 & 9.98 & 287.561 & 287.5 & -0.021 \\
\hline 4 & 1 & 0.03 & 0.49 & 9.06 & 288.624 & 286.5 & -0.736 \\
\hline 5 & 0.97 & 0.03 & 0.49 & 9.98 & 283.282 & 283.5 & 0.077 \\
\hline 6 & 0.98 & 0.03 & 0.49 & 9.82 & 287.186 & 287 & -0.065 \\
\hline
\end{tabular}

\section{CONCLUSION}

(1) Using ultrafine cement as the base material, adding expansion agent, polycarboxylic acid water reducer and retarder, developed a sealing material that meets the requirements of fluidity and expansion performance. It can be seen from the results of the response surface that as the water-cement ratio increases, the fluidity of the material 
also increases. As the content of retarder increases, the fluidity of the drilling seal material continues to decrease. As the amount of water reducing agent increases, the fluidity of the material increases. As the amount of expansion agent increases, the fluidity of the test block decreases.

(2) Orthogonal experiments were designed using the Box-Behnken module in the Design Expert software. Fluidity was the response value, and various test factors (water-cement ratio, water-reducing agent, retarder, and expansion agent) were established and optimized. The quadratic model of time showed a high prediction accuracy.

(3) The influence of each component on the fluidity of the material was obtained using a range and variance analysis and a significance test. These had the following order: $C$ (water-reducing agent) $>A$ (water cement ratio) $>$ $B$ (retarder) $>D$ (expansion agent).

(4) According to the response surface drawn by the binomial polynomial regression equation, the interaction of any two factors was analyzed, and the interaction laws were obtained. These effects had the following order: $A C$ (water-cement ratio, water-reducing agent) $>C D$ (waterreducing agent, expansion agent) $>B C$ (retarder, waterreducing agent) $>A D$ (water-cement ratio, expansion agent) $>A B$ (water-cement ratio, retarder) $>B D$ (retarder, expansion agent).

(5) Combining the orthogonal test results of the response surface analysis method with the fluidity test results of the sealing material, the best experimental conditions for the test are obtained: the water-reducing agent content is $0.5 \%$, the retarder content is $0.03 \%$, and the water-cement ratio is 1 , and the expansion agent content is $8 \%$.

\section{Acknowledgements}

This research is financially supported by National Natural Science Foundation of China (51934007, 51904013), National Key Research and Development Program of China (2018YFC0808000), Youth Science and Technology Talents Support Program (2020) by Anhui Association for Science and Technology (RCTJ202005), Anhui Oversea Returnees Innovation Project Funding (No. 2019LCX001), Key Science and Technology Project of China Coal Energy Group Corporation (202103) and Open Research Fund of State Key Laboratory of Coal Resources and Safe Mining, CUMT (SKLCRSM20KF003).

\section{REFERENCES}

[1] Yuan, L. (2016). Strategic thinking of simultaneous exploitation of coal and gas in deep mining. Journal of China Coal Society, 41(1), 1-6.

[2] Yuan, L. \& Zhang, P. S. (2019). Development status and prospect of geological guarantee technology for precise coal mining. Journal of China Coal Society, 44(8), 2277-2284.

[3] Kang, H. P. (2014). Support technologies for deep and complex roadways in underground coal mines: A review. International Journal of Coal Science \& Technology, 1(3), 261-277. https://doi.org/10.1007/s40789-014-0043-0

[4] Wtrzykowshi, M., Trtik, P., Munch, B., Weiss, J., Vontobel, P., \& Lura, P. (2015). Plastic shrink age of mortars with shrink age reducing admixture and lightweight aggregates studied by neutron tomography. Cement and Concrete Research, 73, 238-245. https://doi.org/10.1016/j.cemconres.2015.03.013

[5] Pantazopoulos, I. A., Markou, I. N., Christodoulou, D. N., Droudakis, A. I., Atmatzidis, D. K., Antiohos, S. K., \& Chaniotakis, E. (2012). Development of microfine cement grouts by pulverizing ordinary cements. Cement and Concrete Composites, 34(5), 593-603. https://doi.org/10.1016/j.cemconcomp.2012.01.009

[6] Gahle, C. \& Kutter, H. K. (2003). Breakage and shear behaviour of intermittent rock joints. International Journal of Rock Mechanics and Mining Sciences, 40(5), 687-700. https://doi.org/10.1016/S1365-1609(03)00060-1

[7] Wu, A. X., Yu, S. F., Han, B., Wang, Y. M., Huang, M. Q., \& Wang, Y. (2014) Optimization of mix-proportion and diffusing rule of super-fine cement grouting slurry. Journal of Mining \& Safety Engineering, 31(2), 304-309.

[8] Zhang, J. P., Liu, L. M., Zhang, F. T., \& Cao, J. Z. (2018). Development and application of new composite grouting material for sealing groundwater inflow and reinforcing wall rock in deep mine. Scientific Reports, 8(1), 1-8. https://doi.org/10.1038/s41598-018-23995-y

[9] Wang, K., Wang, L. G., Lu,Y. L., Sun, X. K., \& Zhang, K. W. (2020). Visual experimental study on the infiltration effect of cement slurry in micro-fractures. Journal of China Coal Society, 45(3), 990-997.

[10] Guo, D. M., He, T. Y., Yang, R. S., Ye, D. S., Zhang, Y. Q., \& Li, C. P. (2017). CT analysis on micro-cement grouting effect for fractured rock sample. Journal of Mining \& Safety Engineering, 34(5), 987-992.

[11] Hogancamp, J. \& Grasley, Z. (2017). The use of microfine cement to enhance the efficacy of carbon nanofibers with respect to drying shrinkage crack resistance of portland cement mortars. Cement \& Concrete Composites, 83, 269272. https://doi.org/10.1016/j.cemconcomp.2017.08.006

[12] Miao, M., Xue, K. W., Miao, F., \& Jiang, W. H. (2018). Influence of Limestone Powder on Hydration Characteristics and Rheological Properties of Cement Paste. Journal of Hunan University (Natural Sciences), 45(12), 90-96.

[13] Zhang, C., Chang, J., Li, S. G., Liu, C., Qin, L., Bao, R. Y., Liu, H., \& Cheng, R. H. (2019). Experimental study comparing the microscopic properties of a new borehole sealing material with ordinary cement grout. Environmental Earth Sciences, 78(5), 149. https://doi.org/10.1007/s12665-019-8165-8

[14] Wongkornchaowalit, N. \& Lertchirakarn, V. (2011). Setting Time and Flowability of Accelerated Portland Cement Mixed with Polycarboxylate Superplasticizer. Journal of Endodontics, 37(3), 387-389. https://doi.org/10.1016/j.joen.2010.11.039

[15] Chen, J. J. \& Kwan, A. K. H. (2012). Superfine cement for improving packing density, rheology and strength of cement paste. Cement \& Concrete Composites, 34(1), 1-10. https://doi.org/10.1016/j.cemconcomp.2011.09.006

[16] Guo, Y. C., Shen, A. Q., Ma, L., Zhu, J. H., \& Wang, X. F. (2010). Microstructure of crack filling material of polymer emulsion superfine cement. Journal of Chang'an University(Natural Science Edition), 30(1), 16-22.

[17] Wang, Q. B., Zhu, Q. K., Shao, T. S., Yu, X. G., Xu, S. Y., Zhang, J. J., \& Kong, Q. L. (2018). The rheological test and application research of glass fiber cement slurry based on plugging mechanism of dynamic water grouting. Construction and Building Materials, 189, 119-130. https://doi.org/10.1016/..conbuildmat.2018.08.081

[18] Du, H. C., Wang, Y. N., He, M. M., Lin, Z. F., \& Lyu, Z. Z. (2019). Study on the Effect of Organic Retarder on the Performance of Cement Modified Emulsified Asphalt Mastic. Materials Review, 33(S2), 254-260. 
[19] Huang, Z. Y., Liu, Y. Q., \& Li, C. W.(2015). Performance Research of Ultra High Performance Concrete Incorporating HCSA Expansion Agent. Materials Review, 29(4), 116-121.

[20] Li, B., Xu, L. H., Gu, Y. S., \& Jia, M. L. (2017). Investigation on influence of HCSA expansive agent on dosage on performance of high-strength self-compacting concrete. Engineering Journal of Wuhan University, 50(1), 90-96.

[21] Feng, J. J., Miao, M., \& Yan, P. Y. (2012). Hydration and Expansion Properties of Shrinkage-Compensating Composite cementitious Materials. Journal of Building Materials, 15(4), 439-445.

[22] Shui, L. L., Yang, H. J., Sun, Z. P., He, Y., \& Zeng, W. B. (2019). Study on Effect Rate and Influencing Factors of Dispersion Effect of Different Types of Superplasticizer. Journal of Building Materials, 22(6), 853-859.

[23] Du, R. R., Zhang, X., Gu, M. D., \& Ji, T. (2019). The Composition Effect and Mechanism of Polycarboxylate Superplasticizers and Early Strength Agent. Materials Review, 33(7), 2461-2466.

[24] Yu, X., Yu, C., Ran, Q. P., \& Liu, J. P. (2018). Retarding Mechanism of Hydroxy Carboxylic Acid Retarder on Cement Hydration. Journal of the Chinese Ceramic Society, 46(2), 181-186.

[25] He, T. S. \& Li, Z. K. (2015). Study on Influences of Polycarboxylate Superplasticizer on Performance of low cement Castable. Materials Review, 29(S1), 351-353, 365.

[26] Shui, L. L., Sun,Z. P., Yang, H. J., Yang, X., Ji, Y. L. \& Luo, Q. (2016). Experimental evidence for a possible dispersion mechanism of polycarboxylate-type superplasticisers. Advances in Cement Research, 28(5), 287-297. https://doi.org/10.1680/jadcr.15.00070

[27] You, B. \& Li, N. Z. (2005). Expansive agent and shrinkagecompensating concrete. Beijing, China Building Materials Industry Book.

[28] Lan, W. T., Wu, A. X., \& Wang, Y. M. (2019). Formulation optimization and formation mechanism of condensate expansion and filling composites. Acta Materiae Compositae Sinica, 36(6), 1536-1545.

\section{Contact information:}

Xin GUO, Postgraduate

School of Safety Science and Engineering,

Anhui University of Science and Technology,

No. 168 Taifeng Street, 232001 Huainan, Anhui Province, China

E-mail: guoxin190510@163.com

\section{Sheng XUE, Prof}

(Corresponding author)

School of Safety Science and Engineering,

Anhui University of Science and Technology,

No.168 Taifeng Street, 232001 Huainan, Anhui Province, China

E-mail: sheng.xue@aust.edu.cn

\section{Chunshan ZHENG, PhD}

(Corresponding author)

School of Safety Science and Engineering

Anhui University of Science and Technology,

No.168 Taifeng Street, 232001 Huainan, Anhui Province, China

E-mail: chunshanzheng@aust.edu.cn

\section{Yaobin LI, PhD}

School of Safety Science and Engineering,

Anhui University of Science and Technology,

No.168 Taifeng Street, 232001 Huainan, Anhui Province, China

E-mail: binyaoli@163.com 